\title{
Picture book support for preparing children ahead of and during day surgery
}

Nilsson E, Svensson G, Frisman G et al (2016) Picture book support for preparing children ahead of and during day surgery. Nursing Children and Young People. 28, 8, 30-35. Date of submission: 29 February 2015; date of acceptance: 20 April 2016. doi: I0.7748/ncyp.20I6.e749

Elisabeth Nilsson

Registered nurse,

Vrinnevisjukhuset, Gamla

Övägen, Norrköping, Sweden

\section{Gunnar Svensson}

Certified registered nurse anaesthetist, department of otorhinolaryngology, Vrinnevi Hospital, Norrköping, Sweden

\section{Gunilla Hollman Frisman}

Assistant professor, department of anaesthetics, operations and speciality surgery centre and department of medical and health sciences, Linköping University, 58185 Linköping, Sweden

\section{Correspondence \\ elisabet.m.nilsson@ \\ regionostergotland.se}

\section{Peer review}

This article has been subject to open peer review and has been checked for plagiarism using automated software

\section{Conflict of interest}

None declared

\section{Acknowledgements}

The authors thank all parents and their children for participating. This study was supported by the Anaesthetics, Operations and Speciality Surgery Centre, Vrinnevi Hospital, and the County Council of Östergötland, Sweden

\begin{abstract}
Aim To develop and evaluate the use of a specific picture book aiming to prepare children for anaesthesia and surgery.

Methods An intervention comparing two different information methods before ear, nose and throat day surgery was performed. The intervention involved using a specific information sheet and a specific picture book. Parents ( $n=104$ ) of children aged 2-12 years completed open-ended questions that were analysed with qualitative content analysis. They were divided into two groups: one group received routine information and one received routine information and the intervention.

Findings The picture sheet and picture book were valuable aids to prepare small children for anaesthesia and surgery by explaining the procedures that would take place. The parents expressed that knowledge of the procedures made them and the child feel secure.
\end{abstract}

Conclusion Peri-operative information through pictures supports children and their parents during day surgery and may be helpful in future healthcare visits.

\section{Keywords}

acute care, anaesthesia, anxiety, child health, day surgery, paediatric nursing, peri-operative

CHILDREN are exposed to painful and unpleasant procedures during hospitalisation (Chorney et al 2012, Cuzzocrea et al 2013). Being in such a vulnerable situation, they can also have difficulties expressing their needs and understanding the procedures carried out during anaesthesia and surgery. Children can exhibit negative feelings and behaviours that complicate the introduction of anaesthesia, such as separation anxiety, avoidance, fear or sadness (Cuzzocrea et al 2013, Fernandes et al 2014). Even the post-operative period may be affected by negative experiences or pre-operative anxiety. Children who experience a high level of peri-operative anxiety also reported to experience a high level of post-operative pain (Kain et al 2006, Chieng et al 2013).

The majority of the information, as well as the preparation the child and their family receive pre-operatively, is usually directed at the parents rather than the child (Buckley and Savage 2010). It is not always obvious to parents how and if they should prepare their child for surgery. For a child, a secure parent can be a good source of support, which is why it is important that the parent is well prepared
(Adams 2011, Fincher et al 2012, Gimbler Berglund et al 2013).

In a multicultural society information that meets the needs of children and parents who are not fluent in the Swedish language, and who are therefore more vulnerable before and during surgery or other painful procedures, is of great importance. Children must be treated with respect, regardless of age and cultural heritage, and they have the right to receive information they can understand. This means that the information given must be adapted to the child's needs to reduce the negative effect associated with the treatment or surgery (United Nations Children's Fund 1989).

Research has shown that distractions in the form of hospital clowns, puppets, targeted books and interactive games have a positive effect on anxiety in children (Tunney and Boore 2013, Dionigi et al 2014, Fernandes et al 2014). In two studies using pre-operative therapeutic play as an intervention, the results showed that therapeutic play with children led to less anxiety and fear before and after surgery for the child. The parents did not experience any influence on their anxiety and fear before or after anaesthesia and surgery, 
but they perceived the therapeutic play to be a helpful preparation for themselves and their child (He et al 2015a, He et al 2015b). Other studies have used web-based pre-operative preparations and video-taped pre-operative information, which have shown good effects on pre-operative anxiety for children and parents before surgery (McEwen et al 2007, Fernandes and Arriaga 2010, Fortier et al 2015).

Different distraction methods have been tested but research in this area is limited. Therefore, adjusted information preparing children for anaesthesia needs to be developed further and tested first among Swedish children before it is tested among children of other origin.

\section{Aim}

The aim of this study was to develop and evaluate the use of a specific picture book preparing children for anaesthesia and surgery.

\section{Method}

A descriptive intervention study was performed using two different pre-operative information methods for children, aged 2-12 years, scheduled for ambulatory elective ear, nose and throat (ENT) day surgery between 2012 and 2015.

\section{Settings}

In Sweden parents are present in the operating theatre until the child is asleep, and postoperatively they are present in the recovery room when the child wakes up. When the child is relatively recovered, after approximately two hours, the child and the parent are discharged from the recovery room to the ENT unit for another 4-6 hours before discharge from the hospital. Depending on the type of surgery there is a routine for how long the child stays in the hospital after surgery -usually 4-6 hours.

\section{Intervention}

A picture sheet and a picture book illustrating the different steps that the child will go through during anaesthesia and surgery were developed (Figure 1). A picture sheet describing the peri-operative procedure was sent to the parents by post together with the surgery appointment. When the child and the parent arrived at the hospital on the day of surgery they were offered the picture book with pictures of the different procedures/steps that would take place during the day. After each step was carried out, the current picture was removed by the child and attached with adhesive tape to the back of the book.
By detaching pictures after each step the child was empowered by having control of the steps performed as well as the next steps that would take place. The child carried the book with them throughout the day - from the waiting room - into the operating theatre, and then to the recovery room.

\section{Participants}

Inclusion criteria were children aged 2-12 years on the waiting list for ambulatory ENT surgery and their parents. The children and the parents were required to understand Swedish and the parents also needed to be literate in the Swedish language.

Participants were recruited on three different occasions. The first occasion (I) took place before the introduction of the picture support. A control group consisting of parents $(n=52)$ were consecutively asked to participate in 2012. They received routine information about the surgery, what the child should eat and drink before and after the surgery, and when they would be discharged after the surgery. The parents were informed about the study on the day of surgery and asked to participate. Both parents signed an informed consent form.

The second occasion (II) took place after the introduction of picture support. An intervention group was consecutively recruited in 2013. Parents $(n=52)$ consecutively received routine information and the picture sheet illustrating the steps of the day of surgery. The parents were informed about the purpose and performance of the study through an information letter requesting them to participate in the study. Both parents signed an informed consent form. The study information was sent to the parents in the intervention group along with the child's surgery appointment.

Figure I. A picture book illustrating the steps during day surgery at the ear, nose and throat clinic

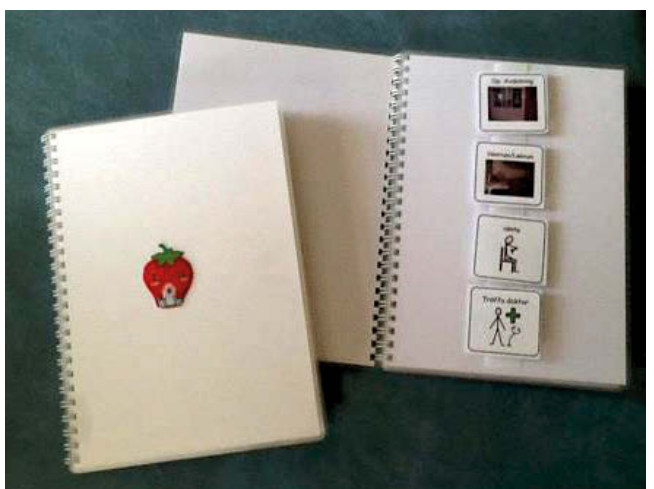

\section{Online archive}

For related information, visit our online archive and search using the keywords 
The third occasion (III) took place in 2014-15. Parents $(n=52)$ whose children had undergone surgery before the introduction of picture support in 2012 were asked by post for permission to review the child's medical record from the date of surgery to determine drug consumption and length of hospital stay. Both parents signed an informed consent form. Based on the age group, 2-12 years, the children's personal identity numbers were identified in the ENT clinic's surgery planning programme and their home address was found.

The picture sheet and the picture book were implemented as ordinary care in 2014 and parents $(n=27)$ whose children underwent surgery in 2014-15 were consecutively asked for permission to review the child's medical record at the time of surgery to determine drug consumption and length of hospital stay. Both parents signed an informed consent form. They were also asked to describe how their child processed the week after surgery by answering two open-ended questions.

The children from occasion II, who were given a surgery appointment with short notice $(n=3)$, did not receive a picture sheet by post due to lack of time. Instead they were asked if they wanted to borrow the picture book when they arrived at the ENT clinic, which most children accepted. Children who wanted to bring a picture sheet home after surgery were allowed to do so.

\section{Data collection}

On the day of surgery the parents in the control group (I) and the intervention group (II) were asked to complete a questionnaire with four open-ended questions. The parents in the intervention group (II) were also asked to answer one additional question. Thereafter, data were collected on the third occasion (III), when the parents $(n=27)$ answered another two questions (Table 1). A protocol for a variety of analgesics prescribed pre-, intraand post-operatively, and during the total hospital stay, was used to collect data from the children's medical records.

\section{Data analysis}

Qualitative content analysis was used to analyse the open-ended questions. The first step aimed to achieve a sense of the whole - the answers were read several times individually. Meaning units relevant to the questions were identified and condensation of the meaning units was then carried out. The condensed meaning units were then merged into categories in agreement between the authors (Krippendorff 2013).

Descriptive statistics, mean, standard deviation, student's $t$-test and the Mann-Whitney U test were calculated for demographic data, use of analgesics and hospital stay. Data were analysed using IBM SPSS Statistics 22.

\section{Ethical considerations}

The regional ethics committee approved the study in accordance with the Helsinki Declaration (World Medical Association 2013). All participants received information about the confidential and voluntary nature of the study and could withdraw from the study at any time.

\section{Findings}

There were 26 and 27 participating children in the intervention and control group respectively. Characteristics of the children are presented in Table 2. The qualitative results are presented in

\section{TABLE 1. Data collection on three different occasions using open-ended questions}

$$
\text { Questions answered on the day of surgery after the procedure }
$$

$$
\text { Control group (I) (n=52) }
$$

Intervention group (II) $(n=52)$

Do you feel that the written information you were sent home with before the visit at the ENT clinic was adequate?

» Did your child bring any of this information with them to the surgical department? If so, how?

Do you think that something is missing in the information sheet you received? If so, what?

Is there anything you think needs to be improved or clarified in the information sheet?
Questions answered one week after surgery

Intervention group (III) $(n=27)$

»Would you please describe as thoroughly as possible how your child processed the visit to the ENT clinic during the week after surgery?

» Did you or your child use the information sheet you received by post before the anaesthesia and surgery? Would you please describe as thoroughly as possible how it was used?

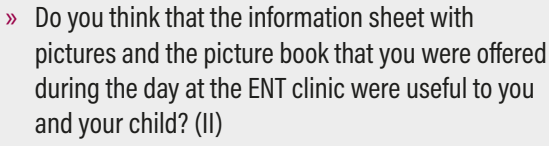

»Do you think that the information sheet with pictures and the picture book that you were offered during the day at the ENT clinic were useful to you and your child? (II) 
three categories: information in ordinary care, the meaning of picture support and the use of a picture sheet post-operatively.

\section{Information in ordinary care}

In the control group most parents $(\mathrm{n}=50)$ were satisfied with the written information they received by post before anaesthesia, but they lacked picture information - a fairy tale or comic pictures - for the child. Some children's appointments had been scheduled at short notice by telephone the day before surgery and there was no time to send information by post. However, they received information orally by telephone. Parents stated that a great number of the children $(n=36)$ had read part of the information before the visit to the hospital.

'We have tried but it's not easy for a 4-yearold boy to understand' (Participant A).

The parents found that the information they received was not addressed to children so they came up with suggestions for further clarification of the pre-operative information. Some parents used the internet to find better information.

'Not aimed at children, perhaps use pictures' (Participant B).

However, there were a few parents who felt they lacked information which was aimed directly at their child such as information through pictures. One parent requested a picture of the hospital and the door to the ward, which they could search for in real life, making the journey to the hospital a joint mission.

'Everyone may still not have a computer at home or the possibility to use one, so written information to the children, perhaps in the form of a comic book or a fairy tale' (Participant C).

One parent expressed a desire to visit the clinic a few days before the surgery to receive information to help explain to their child what was going to happen.

'For us parents it was enough, but the child does not have a chance to read' (Participant D).

Of 52 parents in the control group, 18 lacked information. Some answers focused on practical information such as finding a parking space and a map of the hospital area to make it easier to find the ENT clinic. Some parents wondered about the care after surgery in the recovery room and on discharge from the hospital.

\section{The meaning of picture support}

In the intervention group all parents $(n=52)$ were satisfied with the information and they appreciated the picture sheet and the picture

book. Most of the children $(n=46)$ from occasion II looked at part of the information. The parents and the child read and looked at the pictures in the picture sheet together and discussed what they were going to go through.

'Through the pictures she herself came and asked if we could talk about it, on several occasions' (Participant E).

The parents believed that they and their child had enough preparation before anaesthesia and surgery. They thought that the information was clear and that it contained everything they needed to know.

'Certainly, also good for us as adults' (Participant F).

The parents felt safe when they knew what their child would go through during the day of surgery. Most parents $(n=50)$ answered that they and their child had benefited from the picture sheet that was sent to their home and from the picture book that was used pre-operatively and throughout the entire day. They used it frequently to support their child to understand and keep track of what they were going to go through.

Most of the children had the picture sheet with them on the day of surgery and when

\section{TABLE 2. Characteristics of children participating in the study}

Intervention group $(n=26)$

Boys

Girl

Mean

Standard deviation

Surgery

Tonsillectomy

Tonsillotomy

Adenoidectomy

Tonsillectomy and adenoidectomy

Adenoidectomy and tonsillotomy

Adenoidectomy and microscopic evaluation of the ear (mius)

Adenoidectomy, tonsillotomy and mius

Inhalation induction

Intravenous induction
14

12

5

1.7

1

2

7

6

2

9

3

2

3

8

19 


\section{Write for us}

journals.rcni.com/r/

ncyp-author-guidelines they were offered the picture book they were excited about recognising the pictures. One parent said that the book made their child feel secure and that the book was valuable for the child to follow the different steps and the process during the day.

'The pictures are plastic coated and we use them as a schedule before surgery (Participant G).

The first thing that this child asked for after waking up in the recovery room was the book.

Two of the parents answered that the picture support had not benefited them at all.

'My son is too young to understand'

(Participant $\mathrm{H}$ ).

In the intervention group parents $(n=8)$

lacked some information. There was a request for information about what food they could give their child at home the first days after surgery and when they could eat food as usual.

'More dietary advice/suggestions'

(Participant I).

Use of the picture sheet post-operatively In the last part of the study the parents were pleased about the picture sheet and the picture book. Most of the children $(n=15)$ used the picture sheet at home before the visit to the ENT clinic and a few children $(n=4)$ used the picture sheet at home after the operation.

'He told everybody he met about what he had been through' (Participant K).

All the children enjoyed using the picture book throughout the day of surgery. Most parents felt that the day of surgery had been a positive experience for their child and the child was proud, happy and pleased when discharged from the hospital.

The use of a post-operative analgesic drug (paracetamol) was significantly higher in the control group compared to the intervention group $(P<0.0001)$. For post-operative length of stay there was no statistical difference between the groups.

\section{Discussion}

The authors believe this is the first study evaluating patient information addressed to small children through the use of pre-operative pictures. The findings show that the picture sheet and the picture book were valuable aids to prepare small children for anaesthesia and surgery. The use of visual information made children and parents feel safe and when children feel secure they accept the procedure better, which is a short-term goal for the anaesthetic nurse while establishing a good relationship with the child and parents (Gimbler Berglund et al 2013).
The parents whose children received only written information asked for information addressed to their child and suggested using pictures from fairy tales.

The child kept the picture book with them pre-, intra- and post-operatively during the day of surgery, which gave the child a sense of self-control over the procedures. Knowing what would happen made the child feel secure. Many children may feel abandoned and there is a risk that they can feel that they are being assaulted while sedated.

Uncertainty about what will happen may intensify anxiety, both pre-operatively and post-operatively. Being well prepared can mean that the child is less anxious during the induction of anaesthesia, which may influence anxiety and experience of pain afterwards in the recovery room. Pre-operative anxiety has previously been shown to be associated with more painful post-operative recovery (Kain et al 2006).

Several parents described their appreciation of the picture sheet and picture book. They gave them a sense of control as well, and they could support their child during the day of surgery. Most of the parents did not know what to expect from the day, but with this book they and their child could follow the procedure step by step together. The picture book gave the children and parents a chance to focus on the pictures, which may have resulted in decreasing their anxiety about surgery. Parents with less anxiety can support their children in a safer manner and transmit a sense of security to their child, as confirmed in earlier studies (McEwen et al 2007, Li and Lopez 2008, He et al 2015a). Also, staff in the operating theatre felt that the environment was calmer when a well-prepared child was given anaesthesia.

In today's healthcare system where the surgery schedule is often strained, there is limited time to prepare a child appropriately on the day of surgery (Fortier et al 2015). When comparing different interventions, pharmacological sedation is the most efficient method for decreasing pre-operative anxiety (Kain et al 1998), even though it is not cost effective over time.

Pharmacological sedation only helps the child at a particular time point and does not give the child the possibility to develop strategies for coping with similar situations in the future (Wright et al 2007).

Some children repeatedly visit healthcare services during their childhood and they may feel uncomfortable or anxious about upcoming appointments (Tunney and Boore 2013). For 
these children and parents, a picture sheet and a picture book, in addition to verbal information, may create an opportunity for good two-way communication between the parent and child and help to facilitate participation.

Using pictures for reinforcing verbal language facilitates understanding and is in line with research carried out by Kools et al (2006), who showed that a combination of pictures and written information produces the best results in comparison with only written information. It is important that all healthcare staff provide the same information about the various steps to be implemented. Children, parents and staff who concentrate on the pictures develop a collective understanding that helps to consolidate the communication needs of the child.

The pictures can also be used as working material for staff in various professions, which can provide security when meeting children and parents. Staff that are less experienced in caring for children can be supported by a picture book.

The findings demonstrated that the need for a post-operative analgesic drug was significantly higher in the control group compared to the intervention group - previous studies have also shown that pre-operative preparation reduces the need for analgesics (Tunney and Boore 2013, He et al 2015b). However, as this was a small study, a larger randomised intervention trial is needed to determine the effects of the picture support.

\section{Limitations}

The response rate in this study was poor, which may be due to the fact that many children and parents at the operating theatre were of foreign origin and not asked to participate; a larger number of participants might have given another result. Data collection was performed on three different occasions over a period of three years, which may have influenced the findings.

\section{Conclusion}

Peri-operative preparation with picture support made small children and their parents feel safe and secure about the impending surgery. Preparing small children for anaesthesia and surgery may support all their future contacts with healthcare services.

\section{Implications \\ for practice}

»Picture support can be used in other contexts with andesthesia and surgery, with different healthcare and dental care procedures

» Patients with cognitive disabilities may find such support aids understanding

" Using picture books can be helpful for non-native speakers to understand the procedure being undertaken

\section{References}

Adams HA (2011) A perioperative education program for pediatric patients and their parents. Association of Operating Room Nurses. $93,4,472-481$.

Buckley A, Savage E (2010) Preoperative information needs of children undergoing tonsillectomy. Journal of Clinical Nursing. 19, 19-20, 2879-2887.

Chieng YJ, Chan WC, Klainin-Yobas P et al (2013) Perioperative anxiety and postoperative pain in children and adolescents undergoing elective surgical procedures: a quantitative systematic review. Journal of Advanced Nursing. 70, 2, 243-255.

Chorney JM, Tan ET, Martin SR et al (2012) Children's behaviour in the postanesthesia care unit: the development of the child behavior coding system-PACU (CBCS-P). Journal of Pediatric Psychology. 37, 3, 338-347.

Cuzzocrea F, Gugliandolo M, Larcan R et al (2013) A psychological preoperative program: effects on anxiety and cooperative behaviors. Pediatric Anesthesia. 23, 2, 139-143.

Dionigi A, Sangiorgi D, Flangini R (2014) Clown intervention to reduce preoperative anxiety in children and parents: a randomized controlled trial. Journal of Health Psychology. 19, 3, 369-380.
Fernandes SC, Arriaga P (2010) The effects of clown intervention on worries and emotional responses in children undergoing surgery. Journal of Health Psychology. 15, 3, 405-415,

Fernandes SC, Arriaga P, Esteves F (2014) Providing preoperative information for children undergoing surgery: a randomized study testing different types of educational material to reduce children's preoperative worries. Health Education Research. $29,6,1058-1076$

Fincher W, Shaw J, Ramelet AS (2012) The effectiveness of a standardised preoperative preparation in reducing child and parent anxiety: a single-blind randomised controlled trial. Journal of Clinical Nursing. 21, 7-8, 946-955.

Fortier MA, Bunzil E, Walthall J et al (2015) Web-based tailored intervention for preparation of parents and children for outpatient surgery (WebTIPS): formative evalution and randomized controlled trial. Anesthesia \& Analgesia. 120, 4, 915-922.

Gimbler Berglund I, Ericsson E, ProczkowskaBjörklund M et al (2013) Nurse anaesthetists' experiences with pre-operative anxiety. Nursing Children and Young People. 25, 1, 28-34.

He HG, Zhu LK, Chan WC et al (2015a) A mixedmethod study of effects of a therapeutic play intervention for children on parental anxiety and parents' perceptions of the intervention. Journal of Advanced Nursing. 71, 7, 1539-1551.

He HG, Zhu LK, Chan WC et al (2015b) Therapeutic play intervention on children's perioperative anxiety, negative emotional manifestation and postoperative pain: a randomized controlled trial. Journal of Clinical Nursing. 71, 5, 1032-1043.

Kain ZL, Caramico LA, Mayes LC et al (1998) Preoperative preparation programs in children: a comparative examination. Anesthesia \& Analgesia. $87,6,1249-1255$.

Kain ZL, Mayes LC, Caldwell-Andrews AA et al (2006) Preoperative anxiety, postoperative pain, and behavioral recovery in young children undergoing surgery. Pediatrics. 118, 2, 651-658.

Kools MW, van de Wiel MW, Ruiter RA et al (2006) Pictures and text in instructions for medical devices: effects on recall and actual performance. Patient Education and Counselling. 64, 1-3, 104-111.

Krippendorff K (2013) Content Analysis. An Introduction to its Methodology. Third edition. Sage Publications. Thousand Oaks, California CA.

Li HC, Lopez V (2008) Effectiveness and appropriateness of therapeutic play intervention in preparing children for surgery: a randomized controlled trial study. Journal for Specialists in Pediatric Nursing. 13, 2, 63-73.

McEwen A, Moorthy C, Quantock C et al (2007) The effect of videotaped preoperative information on parental anxiety during anesthesia induction for elective pediatric procedures. Pediatric Anesthesia. 17,6, 534-539.

Tunney AM, Boore J (2013) The effectiveness of a storybook in lessening anxiety in children undergoing tonsillectomy and adenoidectomy in Northern Ireland. Issues in Comprehensive Pediatric Nursing. 36, 4, 319-335.

United Nations Children's Fund (1989) Conventions on the Rights of the Child. www.unicef.org/crc/ (Last accessed: September 8 2016.)

World Medical Association (2013) World Medical Association Declaration of Helsinki: ethical principles for medical research involving human subjects. Journal of the American Medical Association. 310, 20, 2191-2194.

Wright KD, Stewart SH, Finley GA et al (2007) Prevention and intervention strategies to alleviate preoperative anxiety in children: a critical review. Behavior Modification. 31, 1, 52-79, 